\title{
REPRESENTAÇÕES DE PROFESSOR: ENTRE O PASSADO E O PRESENTE
}

\author{
Maria José Coracini ${ }^{1}$
}

\section{Resumo}

Este texto tem por objetivos principais discutir o termo "representação" em várias acepções, principalmente no campo das humanidades, e, em seguida, apresentar algumas imagens ou representações de professor que habitam o profissional, resultantes da análise de um texto publicado na internet. Embora, no final, o autor do texto se revele como não sendo um professor, as imagens que aí se encontram remetem à ideia de que o professor se vê entre o passado e o presente, entre representações "tradicionais", idealizadas, de um profissional que quer educar e instruir seus alunos e representações “pós-modernas” de um profissional que precisa se adaptar ao momento histórico-social em que se encontra, entregando-se às normas da escola e do consumo, entre o sujeito do desejo e o sujeito do imaginário. Adota-se a perspectiva discursivodesconstrutivista, que assume a análise discursiva,atravessado pela psicanálise lacaniana e a desconstrução.

Palavras-chave: Discurso; Desconstrução; Representações; Sujeito; Ensino

\footnotetext{
${ }^{1}$ Doutora em Ciência: Lingüística Aplicada pela Pontifícia Universidade Católica de São Paulo (1988), Livre Docente (2000) e professora titular (2007) em Lingüística Aplicada na Área de Ensino/Aprendizagem de Língua Estrangeira pela Unicamp (2000). Possui pós-doutorado junto ao Centre Inter-universitaireenAnalyseduDiscours et SociocritiquedesTextes (Ciadest) e ao grupo de pesquisa Marges (Marginalisation et Marginalitédanslesdiscours), em Montréal, Canadá (1992-3). Professora titular MS-6 na Universidade Estadual de Campinas (Unicamp). Endereço: Universidade Estadual de Campinas, Instituto de Estudos da Linguagem, Departamento de Lingüística Aplicada. Cidade Universitária, Dist. Barão Geraldo, CEP: 13083-970 - Campinas, SP - Brasil - Telefone: (19) 37881512. Endereço Eletrônico: coracini.mj@gmail.com
} 
CORACINI,Maria José.

\section{INTRODUÇÃO}

É muito comum falar do professor em geral, criticá-lo, seja porque suas aulas são desinteressantes e desatualizadas, seja porque não "domina" a classe, ou melhor, não consegue manter a disciplina, não se faz respeitar e, por isso, os alunos abusam. É muito comum ouvir críticas ao professor que não tem método, não ensina e não agrada o seu aluno, enfim, que está mal preparado, que precisa de reciclagem ou cursos de formação ou treinamento, que não aplica o que aprende nesses cursos, que não tem paciência... Com o reforço da mídia jornalística, o professor recebe críticas de todos os lados: não se leva em conta o quanto precisa trabalhar para poder ter um rendimento mensal satisfatório. Esquece-se também que, muitas vezes, mora longe e tem dificuldades com o transporte coletivo. Num país em que os profissionais da educação estão cada vez mais escassos, por conta do salário, do pouco reconhecimento que a sociedade lhes atribui, qualquer estudante universitário pode substituí-lo, sobretudo, por exemplo, em aulas de língua portuguesa ou de língua estrangeira, desde que conheça a língua: como se bastasse ser falante ou conhecer a gramática de uma língua para ensiná-la. O despreparo fica ainda mais claro! E o descaso, mais acintoso! Daí a reiterada frase desanimadora, pronunciada por alunos e pais: não se aprende inglês na escola!

Entretanto, se o professor é falado por outros, poucas oportunidades the são concedidas de dizer o que pensa sobre si mesmo. Muitas pesquisas que tomam o professor como participante ativo da mesma, em entrevistas, por exemplo, mas poucas, ainda, no âmbito de uma perspectiva discursiva. Dentre estas citem-seEckert-Hoff (2004),Stübe (2008) eCoracini (2011). Como se vê o profissional da educação e como é visto? Em vez de entrevistas, rastreamos alguns sites em que professores falam de si, apontam para as representações de si e do outro de si (o outro que inevitavelmente o constitui). Dentre os textos encontrados, eslhemos um, que parece suficiente para provocar a discussão que se pretende empreender neste artigo a respeito das imagens ou representações de si e do outro. São as representações, que sempre partem do outro, que constituem a identidade de cada um. Daí o interesse do presente artigo.

O termo "representaçõesapresenta diferentes definições conforme a linha teóricometodológica dos autores.Entretanto, por questões de espaço, faremos apenas algumas 
REPRESENTAÇÕES DE PROFESSOR: ENTRE O PASSADO E O PRESENTE

considerações preliminares a respeito,na busca da noção que orientou nosso olhar por ocasião da análise e dos resultados.

Mas, antes, faz-se necessário dizer que, do ponto de vista filosófico, baseamos nossa pesquisa na perspectiva discursivo-desconstrutivista, assim denominada para distingui-la de outras concepções discursivas. Apoiamo-nos, assim, em teorias do discurso, com ênfase nos trabalhos de Michel Foucault, sobretudo no que diz respeito às relações de poder(-saber), de discurso, de formação e prática discursivas; em Freud e Lacan, no que diz respeito a identidade, a sujeito cindido, inconsciente: sujeito da linguagem, do desejo, da falta; no pensamento problematizador de Jacques Derrida, que questiona a predominância da racionalidade, do logocentrismo, do pensamento dicotômico da epistemologia ocidental. Não se pretende fazer tabula rasa das diferenças, mas trazer esses intelectuais ao diálogo, já que concordam naquilo que consideramos essencial: o conceito de sujeito do inconsciente, cindido, por oposição ao sujeito cartesiano, racional e de linguagem, que os três abordam em sua opacidade ${ }^{2}$.

\section{ALGUMAS CONSIDERAÇÕES SOBRE "REPRESENTAÇÃO”}

Em princípio, qualquer coisa pode representar qualquer outra coisa, mas geralmente empregamos representantes próximos de seus representados. Poderíamos utilizar, por exemplo, uma baleiapara representar um palito de dentes, mas essa relação seria, no mínimo, estranha ou inconveniente; entretanto, se utilizássemos girafa para representar um palito de dentes, haveria algo em comum, embora muitos outros traços permanecessem bem diferentes. Geralmente, são utilizadaspalavras como representantes, porque somos seres de linguagem.Trata-se, assim, da representação por semelhança.

Na Idade Média, empregava-se o termorepraesentatio para indicar a rela0ção entre imagem e seu original. O termo é explicado, na Escolástica, por meio de seus equivalentes: os signos estão no lugar das coisas que os causam e daquelas a que eles remetem: (lt.:stare pro), estar no lugar de, por em cena, desempenhar o papel de.

\footnotetext{
${ }^{2}$ Para maiores detalhes a respeito, leia-se, dentre outros, Rosa \& alii, 2015. 
CORACINI,Maria José.

Foucault (1966, p.34), referindo-se à representação baseada na razão e, portanto, na semelhança,pronuncia-sedo seguinte modo:

[...] na vasta sintaxe do mundo, os diferentes seres se ajustam uns aos outros; a planta comunica com o animal, a terra com o mar, o homem com tudo que o cerca. A semelhança impõe vizinhanças que, por sua vez, asseguram semelhanças. O lugar e a similitude se imbricam: crescem limos nos dorsos das conchas, plantas nos galhos dos cervos, ervas no rosto dos homens; e o estranho zoófito justapõe misturando-as, as propriedades que o tornam semelhante tanto àplanta como ao animal. (FOUCAULT, 1966, p. 34).

Souza (2012), em sua dissertação de mestrado, que trata da questão da linguagem e da representação, comenta que

[...] [e]m meados do século XVII, Foucault identifica um acontecimento de ruptura em nossa cultura que provocou uma reconfiguração geral em nosso conhecimento. Nosso autor utiliza o clássico Dom Quixote, para demonstrar o ocaso da episteme da semelhança e a aurora da episteme da representação. Em contraposição a boa parte dos historiadores das ciências, Foucault desconstrói as leituras que atribuem o caráter eminentemente racionalista do conhecimento produzido nesse período à influência das obras de Descartes e Newton. (SOUZA, 2012, p. 10).

É nesse sentido que Foucault (1966) afirma que, no século XVI, as palavras e as coisas remetiam umas às outras, por relação de semelhança, mas que, já na época clássica, ou melhor,no século XVII, a linguagem passa a organizar as coisas para o pensamento: "o mundo enrolava-se sobre si mesmo: a terra repetindo o céu, os rostos mirando-se nas estrelas e a erva envolvendo nas suas hastes os segredos que serviam ao homem" (FOUCAULT, 1966, p. 33).Ou seja, ocorre um deslocamento de uma ordem das razões cosmológicas para uma ordem do discurso enquanto representação (SILVEIRA, 2008). É Foucault quem explica:

[...] isto é, [ordem] da linguagem, na medida em que ela representa - a linguagem que nomeia, que recorta, que combina, que articula e desarticula as coisas, tornando-as visíveis na transparência das palavras. (FOUCAULT, 1966, p. 326-32).

O mundo não é mais o da semelhança, mas o de representação; dá-se aí a divisão entre signo e objeto: as palavras não mais se ligam diretamente às coisas, como ocorria na Antiguidade. O pensamento se organiza pela mensuração e pela ordem; pela mensuração para estabelecer relações de igualdade e desigualdade, pela ordem para a comparação - ato simples 
REPRESENTAÇÕES DE PROFESSOR: ENTRE O PASSADO E O PRESENTE

que dispõe as diferenças estabelecendo séries organizadas. Descartes e os demais filósofos racionalistas estabelecem certezas e verdades, que ordenam o mundo e o pensamento. No século XIX, a visão classificatória, própria do pensamento científico, fundamentada na razão, dá lugar às regularidades históricas, à pesquisa da evolução e dahistoricidade das coisas (FOUCAULT, 1966). Isso constitui uma forte ruptura com a representação clássica: a linguagem não está mais ligada ao conhecimento das coisas, mas à liberdade dos homens (NÖTH, 1995).

Entretanto,estudos da cognição, desenvolvidos do século XIX ao século XX, que tiveram em Charles Sanders Pierce seu grande mentor, trouxeram outra(s) concepção(ões) de representação. É preciso considerar que o paradigma cognitivo não é homogêneo, mas entrecortado por incompatibilidades das diversas vertentes dos estudos da mente. Operando no nível da cognição (inteligência, mente), o cognitivismo considera que os processos de transmissão neurais podem ser interpretados no nível biossemiótico. Assim,

[...] a dinâmica das relações é uma dinâmica de familiarização, onde os objetos, pessoas e acontecimentos são percebidos e compreendidos em relação a prévios encontros e paradigmas [...] a memória prevalece sobre a dedução, o passado sobre o presente, a resposta sobre o estímulo e as imagens sobre a 'realidade'. (MOSCOVICI, 2007, p. 55).

Palmer (1978, p. 212) defende, à maneira clássica, que a representação é, antes de mais nada, algo que está no lugar de outra coisa; é algum tipo de modelo da(s) coisa(s) que ela(s) representa(m). Assim, haveria o mundo representante e o mundo representado. $\mathrm{O}$ mundo representante teria a função de refletir alguns aspectos do mundo representado, funcionando como representação mediada: ela é terceira em meio a um segundo (seu objeto) e seu primeiro (signo); trata-se, portanto, de um modelo mental ou, como denomina Pierce, da semiose.

Com o advento, então, dos estudos da cognição, a representação passou a ser vista como ligada processos mentais. Assim, é possível dizer que a representação mental é o processo pelo qual o ser humano substitui algo real por algo mental. É a unidade básica do pensamento, isto é, o poder de pensar e imaginar o conceito sem ele estar presente. Por meio da representação mental, o sujeito organiza o seu conhecimento. Ela está relacionada à nossa experiência de vida e esta àcultura. Cada um vai representar liberdade, por exemplo, de uma forma diferente, a partir do que aprendeu durante a vida e de seus conceitos sobre o que seja liberdade. É preciso dizer que sem representação mental não há memória (entenda-se bem, memória cognitiva).Aliás, Rumelhart e 
CORACINI,Maria José.

Norman (1988) defenderam a hipótese da equivalência funcional que sugere que, quando vemos um objetoe depois pensamos nele, ativamos a mesma área do cérebro.

Já os estudos sociais, distantes das preocupações mentais ou cognitivas, propõem outra visão. Uma das finalidades das representações sociaisé tornar familiar algo não-familiar, isto é, uma alternativa de classificação, categorização e nomeação de novos acontecimentos e ideias, com que não tínhamos contato anteriormente, possibilitando, assim, a compreensão e manipulação destes a partir de valores e teorias preexistentes, internalizadas por nós e amplamente aceitas pela sociedade.

As representações que fabricamos - a respeito de uma teoria científica, de uma nação, de um objeto, de grupos profissionais etc. - são sempre o resultado de um esforço constante de tornar real algo que é incomum (não-familiar), ou que nos dá um sentimento de nãofamiliaridade. E através delas nós superamos o problema e o integramos em nosso mundo mental e físico, que é, com isso, enriquecido e transformado. Depois de uma série de ajustes, "o que estava longe, parece ao alcance de nossa mão; o que era abstrato torna-se concreto e quase normal [...] as imagens e ideias com as quais nós compreendemos o não-usual apenas trazem-nos de volta ao que nós já conhecíamos e com o qual já estávamos familiarizados” (MOSCOVICI, 2007, p.58).

Mas, é também possível dizer que uma dada sociedade ou um grupo social impõe aos sujeitos modos de pensar, de ver o mundo, de lidar com ele e nele, de considerar o outro, imprimindo, através da linguagem verbal ou visual, formas de representar o que está à sua volta. Poderíamos, neste caso, dizer que as formações discursivas inseridas num dado momento histórico-social, num dado espaço geográfico, admitem certos dizeres e desconsideram outros por sua não pertinência, o que se traduz emdiferentes práticas discursivas, nas quais os lugares parecem predeterminados, embora os discursos estejam sempre em formação, o que lhes confere certo movimento ainda que imperceptível.

Desse modo, ainda parece possível lembrar dos agenciamentos aos quais nos submetemos, involuntariamente - políticos, mercantilistas etc. - que engancham os sujeitos persuadindo-os da verdade que os meios de comunicação, orientados por interesses, muitas vezes escusos, desejam defender. Tal verdade ou verdades, próprias a cada momento histórico-social, constroi(oem) representações de objetos, indivíduos, pensamentos, de modo que mudanças 
ocorrem mais ou menos rapidamente, conforme os interesses daqueles que ocupam lugares de poder. Assim, a concepção de loucura, por exemplo, muda de perspectivas ao longo dos séculos, segundo as crenças e os valores de um dado grupo social, que os organiza de diferentes modos, formando redes de especificação que Foucault define como

[...] sistemas segundo os quais separamos, opomos, associamos, reagrupamos, classificamos, derivamos, umas das outras, as diferentes 'loucuras' como objetos do discurso psiquiátrico (essas grades de diferenciação foram, no século XIX, a alma, como grupo de faculdades hierarquizadas, vizinhas e mais ou menos interpenetráveis; o corpo, como volume tridimensional de órgãos ligados por esquemas de dependência e de comunicação; a vida e a história dos indivíduos, como seqüência linear de fases, emaranhado de traços, conjunto de reativações virtuais, repetições cíclicas; os jogos de correlações neuropsicológicas como sistemas de projeções recíprocas e campo de causalidade circular). (FOUCAULT, 1969, p. 48).

A partir dos comentários acima elaborados, é possível afirmar que a observação das representações sociais é perceptível em muitas ocasiões. Elas circulam nos discursos, nas palavras, veiculadas nas mensagens e imagens midiáticas, cristalizadas nas condutas e agenciamentos materiais ou espaciais. Por exemplo, buscamos compreender, abstrair significados de informações novas e de fatos produzidos em função da proliferação dos centros de pesquisas científicas, das ideias e "filosofias" amplamente divulgadas pelos meios de comunicação de massa, mas também pelas ideias criadas nas ruas, bares e esquinas do senso comum; e as operacionalizamos em nosso cotidiano. A criação e transformação da informação levam a mudanças em nossos valores, que, consequentemente, irão influenciar as diretrizes dos relacionamentos humanos, na forma como o ser humano se percebe no mundo e na relação com o outro - o que era certo para a geração anterior não o é mais, necessariamente,para a geração atual. Digerimos as novas informações e asre-apresentamos, buscando, ao mesmo tempo, enriquecer e transformar nossos esquemas cognitivos anteriores no que for possível e aceitável à nossa idiossincrasia e buscando também adaptá-la a nossos antigos esquemas cognitivos, na busca de manter o nosso mundo estável e seguro, porque

[...] a dinâmica das relações é uma dinâmica de familiarização, onde os objetos, pessoas e acontecimentos são percebidos e compreendidos em relação a prévios encontros e paradigmas [...] a memória prevalece sobre a dedução, o passado sobre o presente, a resposta sobre o estímulo e as imagens sobre a 'realidade'. (MOSCOVICI, 2007, p. 55). 
CORACINI,Maria José.

O contexto histórico das representações sociais se define pelo fato de que elas, ao serem apresentadas como uma modalidade de conhecimento particular que tem por função a elaboração de comportamentos e a comunicação entre indivíduos (MOSCOVICI, 2007), são sustentadas tanto por conhecimentos oriundos da experiência cotidiana quanto pelareapropriação de significados historicamente consolidados.Não resta dúvida, então, de que as representações sociais provêm da cultura, dos valores, crenças e saberes midiáticos ou conhecimentos científicos de um dado grupo social, em constante movimento, ainda que imperceptível, ou, como diria Foucault (1969), das formações discursivas em que se inscrevem os sujeitos sociais.

Fiorin $(2002$, p.44) se refere a Foucault ao afirmar que "[n]a medida em que o homem é suporte de formações discursivas, não fala, mas é falado por um discurso", o que significa que as regularidades discursivas, que camuflam a heterogeneidade do discurso, orientam os comportamentos, atitudes, linguagem, pensamento, relacionamentos num dado momento histórico-social; daí determinados enunciadosserem relevantes numa dada situação de enunciação, marcada pela historicidade, e não serem aceitos em outras situações, momentos e espaços geográficos.

Assim, os seres humanos, sofrendo coerções sociais, amoldam-se,talqual a linguagem que os constitui enquanto falantes inseridos em formações discursivas, e constroemimagens de si e dos grupos sociais aos quais pertencem.Não foi sem razão que Foucault escolheu a análise do quadro "Asmeninas", de Velásquez, para introduzir a sua obra As Palavras e as Coisas (LesMots et lesChoses). É como se esse primeiro capítulojá contivesse ou fosse um resumo do que viriaao longo das páginas seguintes. Afinal,

[...] trata-se de uma representação da representação. Um duplo. E o que é a linguagem,senão esta função de tudo representar? Este olho quenão se cansa de ver? Representações serão sempredatadas. Carregam sempre a marca da sua indelévelcontemporaneidade. Nada mais são que registros. Enesse infindável processo de tudo representar, cabetudo, as ciências, as divagações, tudo que se podenomear, pois por detrás da linguagem, da sua função,está como disse Jakobson o fundamento da cultura. (WANNER, 2010, p. 181).

Como bem lembra Wanner (2010), Foucault (1966) sempre esteve voltado para a história da cultura ocidental, investigandoas mudanças nas noções de representação,mostrandouma distinção entre a representação e o mundo, sobvários ângulos, realizando uma espécie de 
REPRESENTAÇÕES DE PROFESSOR: ENTRE O PASSADO E O PRESENTE

escavação arqueológica. Foucault entende arqueologia como o estudo das diferenças entre história intelectual e fenomenologia, na qual tudo o que percebemos só pode ser reconhecido através da rede de relações sígnicas. Foucaultinteressa-se, então, pelos modos de representação presentes no discurso ou, mais especificamente, na linguagem e nas artes.

As representações sociais e discursivas, portanto, aparecem, no século XX, ligadas ao signo, à cultura, à circulação dos discursos. Passemos rapidamente em revista a concepção de representação, tal como a entendemos, nos domínios da psicanálise e da desconstrução.

Em Freud (1895 [1996]), a tradicional dicotomia entre o lado material, ou do conteúdo ideativo, tradicionalmente identificado como a faceta psicológica e subjetiva do fenômeno mental, e o lado formal, ou do pensamento, também por tradição identificado com a faceta lógica e objetiva, vai assumir a forma da dicotomia representação (Vorstellung) versus pensamento (Gedanke). Os processos perceptivos fornecem o conteúdo representacional dos processos mentais e a experiência do sujeito, relativa a esse conteúdo, fornece seu processamento, os chamados 'processos de pensamento' (THÁ, 2011).Para Freud, pensamento e linguagem são dois domínios diferentes que podem ou não se entrecruzar (THÁ, 2011).

Freud distingue a realidade psíquica e a realidade material/externa. A primeira é mais importante do que a segunda; poisconta mais o modo como foi vivido e sentido um dado factual do que propriamente o fato, se é que é possível afirmar a existência do fato, objetivamente descritível. Não seriam os fatos fruto de interpretação do que se vê ou se vive? Ou melhor, não seriam fruto de representações que trazemos em nosso imaginário ou na esfera do simbólico?

Para Lacan (1949 [1998]), as representações ou imagens (de si e do outro), imagens essas vindas do outro, da relação que se estabelece com esse outro, se dão na esfera social e moldam o comportamento, as atitudes do ego, imprimindo uma ilusão de inteireza, de completude, de totalidade, de verdade a que se dá o nome de "identidade". É preciso atentar para a constituição histórica desse termo: idem (igual) a si mesmo. Mas, ainda segundo Lacan, por ser ilusória, a identidade confunde o sujeito que acredita se ver por inteiro no espelho do olhar do outro (imagem especular). Aliás, o bebê se vê pela primeira vez por inteiro, quando a mãe ou alguém que a substitui mostra sua imagem no espelho, atribuindo-lhe um nome, imagem deformada de si, o avesso de si. Até então, o bebê se via fragmentado: pés, mãos, braços; ele se sente o prolongamento da mãe (do outro). Na verdade, o que ele vê será sempre uma imagem destorcida 
CORACINI,Maria José.

de si mesmo e nunca a verdade de si; esta se encontra no registro do inconsciente, ao qual o sujeito só tem acesso limitado através das formações do inconsciente (FREUD, 1917 [1980]); LACAN, 1957-58 [1999]), tais como sintomas, sonhos, lapsos, atos falhos, chistes, equívocos.

Assim se pronuncia Lacan, a respeito das formações do inconsciente:

No sintoma, assim como nas demais formações do inconsciente, há uma satisfação de desejo, mas essa satisfação é uma "satisfação às avessas" (Lacan, 1957-1958/1999, p. 331) e, conforme Freud, uma "satisfação real" (Freud, 1917/1980, p. 421), para além do princípio do prazer e vinculada à pulsão de morte, demonstrando a aporia do desejo. (DIAS, 2006, s/p.).

Retornemos ao estádio do espelho (LACAN, 1998). O que o bebê vê no espelho é a representação ou a imagem de si, às avessas, como dissemos, imagem que nunca coincidirá com o eu do sujeito, com o que ele é. Essa representação é a primeira de uma série (in)finita de outras que, pouco a pouco, segundo a sua relevânciapara o sujeito, poderão passar ao registro do Simbólico e nele se fixar, levando o sujeito a se reconhecer como bom ou mau, bonito ou feio, honesto ou desonesto, inteligente ou não... Da mesma forma ocorre com as imagens do outro: quem é o outro com quem se relaciona? Como é ele? As representações ou imagens do outro podem se transformar em rótulos ou estereótipos, se o sujeito não estiver atento a essa tendência. Mas, o que é importante assinalar é que as representações - de si, do outro e do outro de si - se constroem, sempre e inevitavelmente, a partir do outro, que vê, julga, define, afirma características que podem evidentemente mudar, com o tempo, mas que podem também deixar marcas profundasno sujeito, sobretudo quando se trata de um outro próximo, querido, como os familiares. Se assim for, a metáfora do espelho não se aplica apenas à imagem do corpo como um todo, mas à identidade do sujeito, que se julga inteiro, iludindo-se, a cada momento, de que tais ou tais traços, tais ou tais valores o constituem definitivamente, ainda que a eles outros traços, outros valores venham metonimicamente se somar. Nesse sentido, a identidade (coincidência do eu consigo mesmo), constituída por feixes de representações (ou imagens) que constituem o imaginário, é uma ilusão ou, como denomina Berry (1991), um sentimento, não no sentido afetivo do termo, mas no sentido de sensação.

Esses mesmos traços poderão se identificar com traço(s) do outro e produzir o que Lacan denomina identificação. Assim, se a identidade não é ilusória, momentos de identificação podem 
ser flagrados, momentos que partiriam do sujeito, de seu inconsciente, onde traços se encontram gravados, e que, em contato com traços do outro, se põem em "movimento", provocando empatia, simpatia ou antipatia, mal-estar diante do outro. Desse modo,é possível dizer que traços de mim representam traços do outro, que traços do outro me representam: o modo como o outro me vê pode se tornar o modo como me vejo, ou seja, como me represento. Nesse caso, o conjunto de representações ou imagens constitui o imaginário, registro do ego, que desejaser o desejo do outro, fazer o que o outro quer para agradá-lo e/ou para pertencer a um determinado grupo.

Se Foucault denuncia a perda da representação na segunda metade do século XX, Derrida (1967)desconstrói a noção de representação, apontando para a sua impossibilidade. Para ele,a representação não pode ser a repetição de uma presentificação que existiria anteriormente. Segundo o filósofo francês, a representação "não é a modificação de um acontecimento de uma apresentação original” (DERRIDA, 1967, p. 50). O representado é um signo de um signo,

[...]pois a representação deve representar uma apresentaçãoentendida como imaginação. [...] Por outro lado, cada repetição acarreta a modificação desse signo em um processo, no qual nada pode existir nem uma primeira nem uma última vez. (SANTAELLA e NÖTH, 1997, p. 22).

Essa impossibilidade se encontra presente na noção de différance de Derrida (1967b), como mostram Santaella e Nöth (1997, p. 25): “A noção de différance, termo criado por Derrida (1967b), propõe o adiamento infinito da presença e a diferença sempre dentro do signo que leva sempre consigo vestígios de outros signos". Um signo é sempre, portanto, constituído de outros signos, como uma língua de outras línguas, um sujeito de outros sujeitos, ainda que se tenha a ilusão de encontrar a unidade e a homogeneidade, estas só encontram lugar no adiamento, no espaço temporal e na temporalidade espacial do traço de união, dos parênteses, que unem e desunem a um só tempo as dicotomias próprias da cultura ocidental, que atribuem a um dos pólos a prioridade hierárquica.

Apesar de concordarmos com Derrida a respeito da impossibilidade da representação tal como é vista pelos clássicos e pelos cognitivistas, consideramos que a perspectiva psicanalítica contempla a representação como o modo como cada um se vê e vê o outro, o que, ainda que ilusoriamente, constitui a identidade e flagra identificações, perceptíveis e sensíveis à análise discursivo-desconstrutivista (CORACINI, 2014a; ROSA \& alii, 2015), efetuadano corpus. 
CORACINI,Maria José.

\section{REPRESENTAÇÕES (IMAGENS) DE PROFESSOR}

É nesse percurso de mão dupla, em que fica difícil discernir o que é de umsujeito e o que é do outro e vice-versa, que escolhemos analisar um texto extraído da internet em que alguém se define como professor, sem nenhuma outra especificação. Vejamos o texto completo:

\section{SOU UM PROFESSOR QUE PENSA...}

Pensa em sair correndo toda vez que é convocado para uma reunião, que certamente 0 responsabilizará mais uma vez, pelo insucesso do aluno.

SOU UM PROFESSOR QUE LUTA...

Luta dentro da sala de aula, com os alunos, para que eles não matem uns aos outros.

Que luta contra seus próprios princípios de educação, ética e moral.

SOU UM PROFESSOR QUE COMPREENDE...

Compreende que não vale a pena lutar contra as regras do sistema, ele é sempre o lado mais forte.

SOU UM PROFESSOR QUE CRITICA...

Critica a si mesmo por estar fazendo o papel de vários outros profissionais como: psicólogo, médico, assistente social, mas não consegue fazer o próprio papel que é o de ensinar.

SOU UM PROFESSOR QUE TEM ESPERANCGA...

E espera que a qualquer momento chegue um "estranho" que nunca entrou em uma sala de aula, impondo o modo de ensinar e avaliar.

SOU UM PROFESSOR QUE SONHA...

SONHA COM UM ALUNO INTERESSADO, SONHA COM PAIS RESPONSÁVEIS,

SONHA COM UM SALARIO MELHOR, UM MUNDO MELHOR.

ENFIM, SOU UM PROFESSOR QUE REPRESENTA...

Representa a classe mais desprestigiada e discriminada, e que é incentivada a trabalhar só pelo amor à profissão.

Representa um palhaço para os alunos.

Representa o fantoche nas mãos do sistema concordando com as falsas metodologias de ensino.

E esse professor, que não sou eu mesmo, mas é uma outra pessoa, representa tão bem, que só não trabalha como ator, porque já é PROFESSOR e não dá para conciliar as duas coisas. (Professores de Niterói/São Gonçalo)

Tomemos os subtítulos do texto. A primeira parte da frase funciona como um refrão, que se repete: "Sou um professor que..."Seria possível preencher a lacuna, deixada pela hipotética 
REPRESENTAÇÕES DE PROFESSOR: ENTRE O PASSADO E O PRESENTE

ausência de complemento, com diferentes representações de professor, dentre as quais as que aparecem logo abaixo, escolha do autor que postou o texto no site, embora estas sejam pouco esperadas.

Observemos a primeira parte dos subtítulos. Em primeiro lugar, chama a atenção o verbo “ser" na primeira pessoa do singular ("sou”), que indicia uma caracterização de si, sujeito do enunciado, seguido de um atributo "um professor", segmento constituído de um substantivo indefinido pelo artigo, cujo efeito de sentido aponta, de um lado, para uma generalização (qualquer professor de qualquer disciplina), o que poderia produzir o efeito de essencialidade, de outro, para uma verdade, já que se trata de uma asserção,ao mesmo tempo em que classifica num único grupo os professores que apresentam as mesmas características, construindo-lhes uma identidade $^{3}$. O refrão tal como se apresenta exige, do ponto de vista sintático, um atributo que remeta ao profissional. A expectativa é, portanto, de um adjetivo ou de uma oração adjetiva.

Observe-se que os termos "profissão", "profissional” e "professor" têm a mesma origem etimológica: “(aquele) que professa”, do latim professum que, por sua vez, vem do verbo profiteri: "declarar perante um magistrado, fazer uma declaração, manifestar-se; declarar em alto e bom tom, afirmar, assegurar, prometer, protestar, obrigar-se, confessar, mostrar, dar a conhecer, ensinar, ser professor" (HOUAISS, 2001). Professar remete aos primeiros cristãos que também foram os primeiros professores da História. Convém lembrar que professor bem poderia ter constituído a primeira profissão, a única sem a qual as demais profissões não poderiam existir, já que todas precisam de professores, não fosse a constatação evidente de que, à maneira do ovo e da galinha, o professor também precisou de outros professores para se(in)formar; daí a afirmação de Foucault (1971) de que é inútil buscar a origem: ela escapa, não se dá a ver a não ser pelo eterno retorno do "já-dito", sempre o mesmo e sempre outro, já que retorna em diferentes momentos da enunciação. O verbo profiteri antecedido pelo prefixo 'pro' (diante de) resultou, com o passar dos tempos, no uso do termo "professor" como aquele que professava ou declarava publicamente que possuía conhecimentos em determinada área e que podia transmiti-los (AIDÉ, s/d).Retornemos ao refrão - que se materializa no verbo "ser", seguido do atributo "um professor" que, por sua vez, é acompanhado do relativo "que",seguido de um verbo acompanhado de reticências. Estas abrem a possibilidade de formas de complemento. Vejamos:

${ }^{3}$ Ler a primeira parte deste artigo a respeito de identidade.

Revista Reflexão e Ação, Santa Cruz do Sul, v.23, n.1, p.132-161, jan./jun.2015

http://online.unisc.br/seer/index.php/reflex/index 
$[\ldots]$ pensa...
$[\ldots]$ luta...
$[\ldots]$ compreende...
$[\ldots]$ critica...
$[\ldots]$ tem esperança...
$[\ldots]$ sonha...
$[\ldots]$ representa...

Se tomarmos o verbo com ou sem complemento (pensa o quê? luta por ou contra o quê? etc.), poderíamos pensarna representação de professorcomo um intelectual, afinal, pensar, compreender, criticar remetem a aspectos cognitivos, a atividades mentais. Mas, "compreender" (ver acima) pode anunciar um tema, assunto ou pessoa (compreende seus alunos) ou, ainda, atributos, atitudes de alguém (por exemplo, compreende o desmazelo ou a preguiça de seus alunos). Entretanto, lutar, ter esperança, sonhar, remetem a uma representação de professor idealista que vê na profissão um modo de fazer algo pelo outro, pela sociedade (lutar por um ideal; ter esperança na juventude; sonhar com um mundo melhor, por exemplo). Intelectual e idealista constituem representações recorrentesde si como professor, construídas ao longo do tempo, que ainda permanecem no imaginário do professor atual. $\mathrm{O}$ passado ainda se faz presente na memória discursiva de cada um... (CORACINI, 2011).

Observe-se que a representação de professor se constrói na materialidade discursiva através de uma oração adjetiva seguida de um verbo de ação - física (que luta; que representa) ou mental (que pensa, compreende, tem experiência; sonha; representa), o que aponta para um professor ativo, dinâmico. Entretanto, os complementos (pensa em quê? compreende o quê? sonha com o quê? etc.),que seguem, nem sempre atestam uma posição ativa da parte do professor; antes, denunciamrepresentações outras do profissional, ou melhor, representações que declaram a derrota de seus ideais e a passividade a que se entregou. Observe-se que o verbo que finaliza o refrão se repete a cada segmento complementar, o que imprime ao texto ritmo como o de uma toada que marca a passagem para outras representações. Tomemos S1.

$S 1$ - Pensa em sair correndo toda vez que é convocado para uma reunião, que certamente 0 responsabilizará mais uma vez, pelo insucesso do aluno. 
"Pensa emsair correndo" não parece ser uma frase comum nas representações tradicionais e/ou idealistas de professor(a), pois, ao mesmo tempo em que aponta para uma certa inércia, para não dizer covardia, apesar da intenção de movimento (“correr”), do profissional (que, de fato, não tem coragem de assim proceder), faz emergir imagens de professor desvalorizado, que sofre o impulso de fugir das atividades propostas pela escola para escapar de situações constrangedoras, como a de ser acusado de ser o responsável pelos maus resultados dos alunos. Esse tipo de julgamento - vestígio do discurso jurídico no discurso escolar - indicia a representação de professor omisso, culpado, incompetente. Não raro, a escola, a família e a sociedade colocam a culpa do insucesso do aluno no professor que, no imaginário social, foge de suas responsabilidades: não sabe ensinar nem se interessa pelos alunos. Mas, esse segmento aponta também para o sentimento de culpa, bastante recorrente na sociedade de tradição judaico-cristã, como parte constitutiva do superego (FREUD, 1996), culpa porque seu aluno não aprende, como se aprender, no sentido de tornar seu o que é do outro, dependesse apenas do professor.Mas essa representação, que torna o professor culpado e o aluno vítima, permanece no imaginário social e, por consequência, no imaginário do próprio sujeito.

É importante também observar que, de acordo com S1 e com experiências pessoais, ser professor numa instituição (nos) obriga aparticipar de reuniões em que se analisam os fracassos dos alunos como se fossemseus (nossos) fracassos. A responsabilidade quase nunca recai sobre o aluno - no sentido de que a este competiria dar uma resposta, responder por seus atos e, no caso, por suas ações em sala de aula -, mas quase sempre sobre o professor, que não sabe ensinar e, por isso, o aluno não aprende; daí o sentimento de culpa. Observem-se, finalmente, os indícios de reiteração - "toda vez que","mais uma vez" - que apontam para a repetição de atos ou ideias que vão constituindo ou, melhor, construindo a identidade de professor incompetente. Afinal, a identidade é sempre construída pelo outro, pelas representações que vêm do outro (DERRIDA, 1996; LACAN, 1998; FOUCAULT, 2001a).

Responsabilizar o professor pelo fracasso de seus alunos constitui, ainda, uma atitude própria da sociedade de consumo, em que tudo e todos são produtos a serem descartados quando não funcionam bem ou já estão ultrapassados. Seguindo essa forma (es)vazia(da)de pensar, que aponta para uma certa compreensão da (pós-)modernidade ${ }^{4}$ (CORACINI, 2014b), a

\footnotetext{
${ }^{4}$ Para uma discussão sobre o que se denomina pós-modernidade, ler, dentre outros, Coracini (2014). 
CORACINI,Maria José.

aprendizagem ou o ensino constituem uma mercadoria: o aluno (ou seus pais) compra o produto e exige garantia da qualidade. Assim, sobretudo na rede particular de ensino (mas não apenas), os professores não são mais considerados educadores, formadores, mas apenas informadores, gestores, meros aplicadores de metodologias consideradas eficientes, em que a tecnologia tem um lugar privilegiado, por sua importância no mercado nacional.

Esse recorte permite, ainda, as perguntas: professor pensa? Ou é pensado? A voz passiva (“é convocado") e o verbo "responsabilizar alguém”, que remete a um ato da parte da direção da escola - representada, no caso, pelas reuniões, onde o professor "será responsabilizado" (mais uma frase que, embora de forma camuflada, tem o efeito de voz passiva). O que se quer do professor? Que ele se sub-meta ao sistema educacional e ao projeto da escola.

Mas, a representação de professor como "lutador" é também muito recorrente, no imaginário do passado que persiste, como forma idealizada de ser, no presente: lutador no sentido de trabalhador, alguém que enfrenta, muitas vezes, três turnos para poder ter uma vida digna. Entretanto, essa seria a representação que se vê anulada pela sequência, como se percebe em S2:

\section{S2 - Luta dentro da sala de aula, com os alunos, para que eles não matem uns aos outros. Que luta contra seus próprios princípios de educação, ética e moral.}

Professor-lutador, professor que luta ou a luta do professor (se desconsiderarmos o refrão), luta contra ou a favor de quê? Afinal, a luta se dá entre, ao menos, duas pessoas, no caso em questão, professor e alunos. Observe-se que o professor "luta com os alunos", luta ao lado dos alunos, contra os próprios alunos, que, por sua vez, lutam entre si. Então, a luta é do professor e dos alunos. As lutas - no plural - são físicas e não abstratas (lutar por um ideal, por exemplo), ocorrem em sala de aula e se imbricam umas nas outras, de modo que aula é sinônimo de luta; e quem seria o vencedor? O professor parece que não é, porque também "luta contra seus próprios princípios",o que significa lutar contra seus princípios de educação, de ética e de moral. Mas, é possível que estejamos frente a um lapso: o professor se representa comoeducador, um ser ético com moral, mas desliza, graças à troca, possivelmente inconsciente, entre "por" e "contra".

Mas, outro efeito de sentido também emerge dessa mesma frase: o professor se vê forçado a entrar na luta com os alunos, embora tal atitude contrariea sua concepção de educação, de ética e de moral. Por que trazer à baila, ao lado de educação, os termos "ética" e "moral"? Numa 
REPRESENTAÇÕES DE PROFESSOR: ENTRE O PASSADO E O PRESENTE

representação idealista, a ética do professor - ética entendida como responsabilidade, resposta ao outro - consiste em estar sempre ao lado do aluno e não em luta com (ou contra) ele. Do ponto de vista da moral, ligada a um conjunto de valores, religiosos ou não, a luta em sala de aula, com certeza, não corresponderia a um valor. Assim, o professor fracassa; se ele quiser manter seu emprego, precisa abdicar de seus valores para agir de acordo com as condições de trabalho, com a situação que se lhe apresenta. Imagem de professor que se sente frustrado diante da realidade de sala de aula, tendo que abdicar de seus ideais, lutando paradoxalmente contra eles, ou melhor, contra si mesmo.Esse paradoxo se vê reforçado pelo sentido de luta que desliza da luta física, corporal para a luta incorpórea, abstrata, ideológica ${ }^{5}$.

Passemos a S3:

\section{S3 - Compreende que não vale a pena lutar contra as regras do sistema, ele é sempre o lado mais forte.}

S3 se refere a um professor que compreende- apre(e)nde com o outro, com as próprias experiências - que é preciso se (con)formar (se forma(ta)r) às regras impostas pelo sistema educacional, como se elastivessem existência própria e não decorressem de relações de poder existentes na sociedade, em que uns fazem as regras e os demais a elas obedecem.

S3 remete também à "luta", mas para desqualificá-la, quando o poder está do lado do sistema (conjunto de leis), que, neste caso, constitui "o lado mais forte", o lado do vencedor.Atente-se para o advérbio de tempo "sempre" que aponta para a impossibilidade de mudanças. Ao professor com seus valores e ideais cabe o lado mais fraco, o lado daquele que sempre perde. Essa comparação implícita destitui o professor do lugar de vencedor, recorrente no imaginário tradicional, colocando-o, então, no lugar do perdedor.Cabe observar que a negação ('não') traz consigo o seu contrário: como por denegação, a afirmação se faz presente - vale a pena lutar contra o sistema..., afirmação que o advérbio "sempre" e seu oposto subentendido (nunca), torna impossível - para quêlutar se, de antemão, a luta está perdida? Para que um seja sempre vencedor, o outro nunca o será ou será sempre perdedor.

O mesmo professor, que se encolhe e recolhe diante do sistema que dita as regras, se diz "crítico". Observe-se S4:

\footnotetext{
${ }^{5}$ Termo que remete a ideias.
} 
S4 - Critica a si mesmo por estar fazendo o papel de vários outros profissionais como: psicólogo, médico, assistente social, mas não consegue fazer o próprio papel que é o de ensinar.

Segundo S4, o professor sabe qual é o seu papel enquanto profissional do ensino e, por isso, critica a si mesmo por exercer o papel de outros profissionais. Essa é uma imagem que reaparece com muita frequência em relatos de professores: o professor afirma fazer o papel de psicólogo, de médico, de assistente social, às vezes, até de mãe ou de pai (ECKERT-HOFF, 2004). Fazer o papel de outro, por(-se) em cena, é representar no sentido de se colocar no lugar do outro, ou assumir posições sujeito outras, para ser como o outro ou pelo menos imitá-lo, como no teatro, no cinema, na televisão. No caso do(a) professor(a), em S4, trata-se de posições subjetivas $^{6}$ que ele(a) assume em sala de aula, do ou no lugar daquele que deveria apenas ensinar. Ainda hoje, apesar das diferenças ocorridas ao longo do tempo, o lugar de professor e o lugar de aluno se mantêm na prática discursiva de sala de aula, lugar esse que é regulado ou regrado,isto é, que apresenta regularidades (e também divergências, descontinuidades), de modo que é possível, apesar das diferenças, reconhecer quando se trata ou não de uma sala de aula.

De acordo com Foucault (1969), a prática discursiva constitui o conjunto de regras que definem num dado momento histórico-social, em uma dada região geográfica, o comportamento, as atitudes, o pensamento, a expressão verbal ou não de um grupo social. Entretanto, a posição discursiva é definida pela posição sujeito, ao mesmo tempo em que esta define aquela, caracterizando a complexidade de todo discurso, que é sempre heterogêneo, sempre atravessado por fios de outras formações discursivas, constituindo, assim, a sua rede. Se o lugar é mais estável, obedecendo à ordem do discurso num dado momento sócio-histórico, a posição sujeito é móvel, conforme as necessidades impostas e expostas pela situação enunciativa (FOUCAULT, 1971); assim, o professor pode, num dado momento, assumir a posição de psicólogo, enfermeiro

\footnotetext{
${ }^{6}$ O discurso, que Foucault (1969) aborda sob a denominação de formação discursiva, cuja concretização se dáem práticas discursivas, é constituído de lugares discursivos; desses lugares, o sujeito enunciador pode assumir diferentes posições sujeito. Nas palavras de Foucault (1969, p. 123), "um único e mesmo indivíduo pode ocupar, a cada vez, numa série de enunciados, diferentes posições e assumir o papel de diferentes sujeitos". Por exemplo, na prática discursiva de sala de aula, professor e aluno constituem dois lugares, que podem ser ocupados por qualquer indivíduo. Em cada lugar, o sujeito pode assumir a posição de psicólogo, de mãe, de enfermeiro(a); a posição enunciativa é perceptível pela análise dos enunciados. Assim, do lugar de professor (aquele que ensina algo a alguém), o sujeito assume traços que remetem à função de psicólogo, de amigo etc.
} 
REPRESENTAÇÕES DE PROFESSOR: ENTRE O PASSADO E O PRESENTE

etc., sem, de fato, ser psicólogo ou enfermeiro. Isso significa que algum traço desses profissionais constituem o imaginário e, portanto, as representações que habitam o sujeito e que podem se materializar em atitudes, verbalizações, comportamentos.

Mas, o mais surpreendente é que, embora reconhecendo seu lugar de professor em sala de aula, definido sobretudo pela tarefa de ensinar, ele afirma que não consegue exercer essa função (S4); se não consegue ensinar, o aluno também não consegue aprender, o que se justifica pela relação que se estabelece no imaginário social (senso comum) entre ensinar e aprender (um não existiria sem o outro). O verbo "conseguir" na forma negativa e o articulador que garanteuma certa oposição entre as ideias, marcam, na materialidade linguística, essa contradição, que funciona como um paradoxo cada vez mais recorrente nas escolas e universidades brasileiras: o professor assume outras funções deixando de lado, ainda que a contragosto, a principal que é a de ensinar.Mais uma crítica ao professor e à escola!Qual seria a razão: falta de formação? Falta de tempo? Indisciplina dos alunos? Exigências escolares que o desviam de sua principal atividade? Talvez todas essas ou nenhuma delas.

Continuemos.

55 SOU UM PROFESSOR QUE TEM ESPERANCA... E espera que a qualquer momento chegue um "estranho" que nunca entrou em uma sala de aula, impondo o modo de ensinar e avaliar.

Uma vez mais, quebra-se a expectativa das imagens (ou representações) suscitadas pela frase "sou um professor que tem esperança" ou que "espera". Afinal, espera-se sempre algo de bom; tem-se a esperança de que algo considerado positivo aconteça. Entretanto, nesse caso, o professor espera - não no sentido de ter esperança mas de aguardar (ter esperança resvala para aguardar) - que um absurdo aconteça: um novato ou alguém não formado, que não tem experiência alguma na profissão, virá, a qualquer momento, impor “o modo de ensinar e avaliar". Absurdo e surpresa ao mesmo tempo, que pode acontecer ou que já aconteceu ou está acontecendo.

Chama à atenção as aspas na palavra "estranho". Sabe-se, na esteira de AUTHIERREVUZ (1998), que as aspas constituem a marca explícita de uma das formas de heterogeneidade representada. Isso significa que esse sinal gráfico representa, no sentido de 'apresenta', torna 
CORACINI,Maria José.

novamente presente, na materialidade linguística, a voz de outro, outra voz, transformada, que remete o dizer a um "já-dito" (FOUCAULT, 1971). Mas, o efeito de sentido que produz o uso das aspas é de estranhamento, de acontecimento inusitado ou que, pelo menos, assim deveria ser: a presença de um desconhecido, completamente inexperiente,impondo formas de ensinar e avaliar, tarefas intrínsecas ao profissional que se denomina professor. Observem-se os termos "estranho", inexperiente, imposição: o último destoa dos demais, na medida em que um estranho e inexperiente não é legitimado ou autorizado a impor suas ideias a pessoas mais experientes, ponto de vista que parece legitimado pelo imaginário social.

Passemos ao segmento seguinte.

\section{S6 - SOU UM PROFESSOR QUE SONHA...}

SONHA COM UM ALUNO INTERESSADO,

SONHA COM PAIS RESPONSÁVEIS,

SONHA COM UM SALÁRIO MELHOR, UM MUNDO MELHOR.

"Sonhar" é um verbo que, em geral, solicita um complemento positivo, para fazer sentido no imaginário social: "sou um professor que sonha..."; uma vez mais, as reticências permitem uma série de complementos (com um mundo melhor, com sucesso etc.).O verbo sonhar introduz o que Freud (1911) denominou princípio do prazer, por oposição ao princípio de realidade, que o sonho esconde, abafa...Sonhamos com o que não corresponde à realidade, mas que constitui parte de nossos desejos. Assim, se o professor sonha com um aluno interessado, com pais responsáveis, com um salário melhor, com um mundo melhor, é porque esse professor representa o aluno como desinteressado, os pais como irresponsáveis, o seu salário como aquém da expectativa e o mundo como não muito bom. Observe-se, sobretudo, a letra em caixa alta de todasas frases ligadas ao "sonho", negritadas e com espaço duplo (ver o texto integral acima) como se cada frase constituísse uma sequência separada das demais, unidas pelo desejo e, portanto, pelo sonho. Embora não se trate de um sonho que se produz durante o sono, é possível dizer que se trata de um sonho também ligado ao desejo de retrocesso no tempo e no espaço. Hoje, parece impossível que esses sonhos se realizem; muitos acreditam que a escola (alunos, pais), os salários e, portanto, o mundo eram melhores há anos atrás, quando o sujeito do desejo (LACAN, 1998) se via atrelado ao "nome do pai", quando havia regras e leis justas e benéficas, quando o nome do 
REPRESENTAÇÕES DE PROFESSOR: ENTRE O PASSADO E O PRESENTE

pai, simbolizando a autoridade reconhecida e legitimada política, social e religiosamente, ordenava o mundo e o orientava.

Mais uma marca gráfica: a mudança de cor - azul nas letras, azul no sonho, sonho azul: um professor que sonha acordado: aluno interessado, pais responsáveis, salário melhor, mundo melhor! Ilusão, sonho, idealização. Nada disso é possível porque os seres humanos são constitutivamente contraditórios; carregam consigo o que Freud (1938 [1996b]) denomina “pulsão de morte”, cujos sintomas mais comuns são violência, desânimo, revolta, desamparo.

Estranha representação, contrária a qualquer expectativa - como, aliás, ocorre também nos outros recortes -, de um professor que tem esperança: afinal, por que um "estranho" não poderia ensinar a ensinar ou a avaliar? Pressuposto de que o professor experiente sabe o que é melhor para o aluno, sabe o que faz e como faz, sabe como e o que avaliar. Professor plenamente consciente que não sabe lidar com o inesperado, com o novo, com o diferente! Professor que impõe, mas não aceita imposições! Professor que se lastima porque a realidade de sala de aula, a realidade da instituição escolar não corresponde às suas expectativas, ao ideal que construiu, a partir de um imaginário em que o ser humano não se faz presente...Mas pensa tudo poder resolver.

Aluno interessado... em quê? No que o professor quer que ele se interesse? Ou interessado porque o professor, de modo indireto, despertou nele o desejo de aprender, de saber, de partilhar, de pesquisar, de ler, de escrever... ou de adentrar em discursividades outras via línguas-culturas desconhecidas? Sonha com pais que respondam pela educação de seus filhos. Se sonha com tudo isso é porque nada disso ocorre na realidade do dia a dia. Nesse caso, a afirmação ligada ao verbo "sonhar" carrega consigo a sua negação: se sonha com pais responsáveis é porqueos pais não são responsáveis; se sonha com um mundo melhor é porque o mundo não vai bem... e assim por diante.

Mas, esse professor também representa, isto é, se faz representante s, mas também representa ou encena, como se lê em S7:

S7 -Representa a classe mais desprestigiada e discriminada, e que é incentivada a trabalhar só pelo amor à profissão.

Representa um palhaço para os alunos. 
CORACINI,Maria José.

Representa o fantoche nas mãos do sistema concordando com as falsas metodologias de ensino.

E esse professor, que não sou eu mesmo, mas é uma outra pessoa, representa tão bem, que só não trabalha como ator, porque já é PROFESSOR e não dá para conciliar as duas coisas.

O sentido de "representar", no trecho acima,certamente, não carrega o sentido que lhe tem sido atribuído nos resultados de análisecomentados até aqui. Observem-se os complementos: representa a classe...; representa um palhaço...; representa o fantoche...; representa o professor. No primeiro caso, o professor $\mathrm{X}$ (que pode ser qualquer um ou todos ao mesmo tempo) se encontra, juridicamente falando, no lugar de todos os demais professores: ele os representa de forma legítima, já que pertence à mesma classe profissional. Nos demais casos, “representar"aponta para atuar, encenar, por em cena, (re)apresentar outro, o outro que, não raro, habita o sujeito.

Atente-se para as últimas linhas do texto. Ruptura de expectativa: aquele que escreve em primeira pessoa,declaranão ser professornem "um" professor. A primeira pessoa do verbo 'ser'corresponde apenas ao sujeito do enunciado.O sujeito da enunciação poderia ser um ator. É possível, então, afirmar que todas as asserções que constituem o texto, todas as representações daí extraídas remetem a um professor ou tão somente à sociedade? Nem a um nem a outro, ou melhor, aos dois. Falar do outro é também falar de si, disso não há dúvidas; é, pelo menos, expressar sua opinião, colocando-se no lugar do outro, portanto, a partir do outro.Talvez como ator ou como professor. Certamente, como ator e como cidadão que, conhecendo a vida do professor brasileiro construiu representações a respeito do profissional. É interessante observar o efeito de sentido de "só não trabalha como ator porque já é professor e não dá para conciliar as duas coisas", proveniente de só não é X porque já é Y, o que produz o efeito de antecipação de Y que impede que seja X; mas, ser Y é também ser X; observem-se as frases: representa o fantoche do sistema...; representa o palhaço dos alunos... Não é palhaço nem fantoche, mas age como se fosse...As duas atividades profissionais são colocadas lado a lado: o professor representa bem, como se estivesse no teatro (ou no circo?), mas não pode ser as duas coisas - ator e professor; talvez não possa conciliar as duas profissões, mas o fazer do professor, segundo o recorte apresentado, é perpassado, costurado por fios da profissão de ator: mais uma posição que o professor assume em sala de aula, sem, de fato, assumi-la. 
REPRESENTAÇÕES DE PROFESSOR: ENTRE O PASSADO E O PRESENTE

Um professor: um, não, todos! Só no último recorte é que o "um" (artigo indefinido ou numeral?) se revela como "todos", classe socioprofissional, "o professor", materializado pelo artigo definido ou pela ausência de artigo.

\section{RESULTADOS E DISCUSSÃO}

Resultam da análise efetuada as seguintes representações de professor, subjacentes aos recortes apresentados, camufladas pelas reticências dos subtítulos, pela denegação, pelos articuladores de tempo, por exemplo: ser professor é pensar, compreender, lutar, criticar, sonhar, ter valores: ser ético e ter moral. Mas, de modo conflituoso e até mesmo doloroso, outras tarefas e funções lhe são imputadas, e outras representações, próprias do mundo contemporâneo, também denominado pós-moderno, são construídas. São elas: o professor é responsável pelo insucesso do aluno; o professor é responsável pela disciplina e pelo ambiente de sala de aula; o professor é aquele que obedece ao sistema e às suas regras; o professor é aquele que exerce diferentes funções em sala de aula, desde que seja necessário, preenchendo as lacunas da família; o professor é aquele que se dispõe a mudar de atitude e de metodologia se a escola assim o quiser; o professor é compreensivo com relação ao aluno, aos pais, pois estes são clientes e pagam o seu salário; o professor não reclama do salário que recebe, já que é altruísta (trabalha por amor); professor é aquele que é submisso aos alunos e ao sistema. Na visão do professor, cujas representações são tradicionais, ele é um palhaço, um fantoche, um covarde. E isso o faz sofrer...

Observe-se, no percurso das representações aqui levantadas, como estas revelam uma torção, responsável pela tensão e conflito metaforizado na banda de Moebius (LACAN, 1966-67 [2008]) ou na doublebind (DERRIDA, 1995). Esta, tanto quanto a fita de Moebius, apaga a polarização entre as dicotomias e se marca pela indecidibilidade entre os opostos. A tensão se produz quando as duas pontas da fita, na figura de um oito, já se encontram torcionadas, anulando a polarização direito/avesso. Tomando como ponto de partida as representações de si, do professor constituído por valores do passado, passamos às representações ou imagens que, aparentemente, se opõem às primeiras, por se constituírem no presente da (pós-)modernidade 
CORACINI,Maria José.

(CORACINI, 2014b), em que os valores são outros: dinheiro, objetos descartáveis, fugacidade de tudo e de todos; por fim, chega-se às imagens que só são possíveis se vistas da perspectiva do passado.

É exatamente nessa torção, que promove o conflito, que se pode considerar a profissão de professor como uma das que sofrem de assédio moral, por conta da "carga emocional e do forte investimento nas relações humanas, que fragilizam as pessoas” (HIRIGOYEN, 2014, p. 41), geram o medo (do outro, das agressões, de perder o trabalho, de perder a autoridade etc.), a insegurança diante da perda da autoridade e dos parâmetros do passado, como comenta Hyrigoyen (2014, p. 78):

O que fragiliza as pessoas é a ruptura com os antigos sistemas de defesa e o enfraquecimento do poder regulador das instituições coletivas. Aos modelos fundados na obediência e no interdito veio substituir uma exigência crescente de autonomia e liberdade ${ }^{7}$.

Como é possível observar pelos recortes comentados na seção anterior, as representações de si que habitam ainda hoje o professor de qualquer disciplina funcionam à maneira da banda de Moebius como uma torção que anula os opostos, as contradições: as representações tidas como tradicionais, que habitam, ainda hoje, o profissional da educação, têm sua continuidade retorcida nas representações que o momento histórico-social lhes atribui. Assim, não há uma oposição radical entre passado e presente, mas uma continuidade na torção, sob a forma de um oito, do direito que se torna avesso e do avesso que se torna direito. O texto aqui trazido e analisado aponta para o que acaba de ser dito.

\section{5 (IN)CONCLUSÕES}

Para finalizar, observe-se que as representações de si, ainda que sejam representações ou imagens de alguém que "representou" ou encenou ao longo do texto o papel de professor, encobertas pela denegação, pelos articuladores de tempo, pelas afirmações enfáticas, carregam

7 Em francês: “Cequifragiliselespersonnes, c'estl'éclatementdesancienssystèmes de défense et l'affaiblissementdupouvoirrégulateurdesinstitutionscollectives. Auxmodèlesfondéssurl'obéissance et l'interdit est venue se substituer une exigencecroissante d'autonomie et liberté". 
REPRESENTAÇÕES DE PROFESSOR: ENTRE O PASSADO E O PRESENTE

consigo representações do outro - do aluno, dos pais, da escola, da sociedade.Trata-se de um outro, decepcionado como o professor, porque a realidade do presente não mais atende às expectativas do passado; frustrado, porque a sociedade, hoje, exige atitudes que o desprestigiam como professor, que o agridem, que o tornam inferior diante do aluno e diante de si. Essa realidade funciona, como vimos, para o professor como um assédio moral, que, cada vez mais, o incapacita para a profissão, torna-o solitário com suas derrotas, deprimido por ver as representações do passado que o habitam e que, provavelmente, o levaram a escolher a profissão, em conflito com representações do presente, que dele exigem tolerância, paciência, amor e persistência.

Derrotado, desprestigiado, discriminado. Mas, não é só ele: esses sentimentos atingem a todos os que com ele compartilham a profissão. Essa é a representação fundamental de professor na sociedade dita (pós-)moderna. Palhaço para os alunos - ator. Fantoche para o sistema que impõe metodologias sem levar em conta a história do professor.Assim, é possível dizer, a partir do texto analisado, que o professor é, no sentido foucaultiano, um (in)fame(FOUCAULT, 2006): sem fama, ilustre desconhecido, que só se torna famoso quando faz algo absolutamente contrário às expectativas da instituição ou da sociedade.

Professor-ator que não é ator: é e não é; afinal, não pode ser ele mesmo, tem de ser outro em sala de aula: finge, atua, faz de conta, luta, se frustra! Não pode ser o que pensa que é. Mas, como saber quem, de fato, é (somos), como deve(mos) agir em cada circunstância, quando se trata de sala de aula, a não ser que internalizemos e assumamos uma identidade que ilusoriamente parece fixa, estável, coerente, racional, consciente e, portanto, apaziguadora. Discurso da vítima, do ressentido, do derrotado! E isso, se pensarmos sem fazer uso completo da razão, do logos, isto é, se conseguirmos pensar deslocando-nos de nossa racionalidade, o que não é fácil;afinal não somos tão racionais, lógicos, coerentes quanto gostaríamos ou quanto gostaria nossa cultura ocidental; somos,sobretudo, menos controladores de nós mesmos - do que dizemos e fazemos - e dos outros! Como, então, ter certezas, verdades ou a verdade, conhecimentos absolutamente indispensáveis para o outro (aluno) no processo de sua formação para a ciência? Torna-se necessário problematizar, então, o conhecimento objetivo, a verdade, a ciência, que anulam a emergência da subjetividade (CORACINI, 2007). 
CORACINI,Maria José.

Trata-se da luta "contra as regras do sistema", luta que é negada, porque a derrota precede toda ação... Professor derrotista porque se sente derrotado. Que professor é esse, que não reagediante do mais forte, diante do poder; afinal, trata-se de um poder que oprime, do poder soberano? Ou de relações de poder? O sistema educacional brasileiro se coloca como aquele que negocia, que compreende o professor, mas, o professor não representa as regras do sistema (ou o próprio sistema) como passíveis de mudança, mas como fixas, inalteráveis, imutáveis.

Para terminar, vale atentar para a indeterminação do termo "professor" no texto analisado, em que o gênero é esquecido, em que as peculiaridades de cada um - na profissão ou na vida particular - são eliminadas, em que cada qual se reconhece nas generalizações que tornam os indivíduos uma categoria profissional, um grupo com identidade, ainda que essa identidade esteja em mudança - ou talvez em crise? - homogeneização que abafa, afoga as diferenças, a heterogeneidade constitutiva de toda subjetividade. E por falar em subjetividade, onde está o sujeito num texto em que ele não tem chance de emergir? Seria o sistema o responsável por esse abafamento, pelo sofrimento da anulação do sujeito? Talvez sim, mas o certo é que há identificações possíveis e impossíveis ao mesmo tempo num texto cujo autor representa, põe em cena o outro de quem ele se distingue e, ao mesmo tempo, com quem se identifica pela simples existência necessária do professor em sua vida. Esse professor se encontra no entremeio, no espaço entre as oposições, entre ser e não ser, saber e não saber, conhecer e não conhecer, ter autoridade e não ter, ser livre e se submeter.

\title{
REPRESENTATIONS OF TEACHERS: BETWEEN THE PAST AND THE PRESENT
}

\begin{abstract}
This paper aims at discussing the word "representation" in different meanings, mainly in the field of human studies, and to present some images or representations of teachers, which inhabit the professional. These representations result from the analysis of a text presented in the internet. Although, at the end, the author of the text introduces himself as not being a teacher, the representations we can perceive drives to the idea that the teacher is between the past and the present, between traditional representations of a professional, who intends to educate, instruct,
\end{abstract}


and "post-modern" representations of a professional, who needs to adapt himself to the sociohistorical moment in which he lives, accepting the school consumerism rules, between the subject of the desire and the subject of the imaginary. The theoretical orientation adopted is constituted by discourse, interwoven with the lacanian psychoanalysis, and the deconstruction, that is named discursive-deconstructionist approach.

Keywords: Discourse; Deconstruction; Representation; Subject; Teaching

\section{REPRESENTACIONES DEL PROFESOR: ENTRE EL PASADO Y EL PRESENTE}

\section{Resumen}

Este artículo tiene dos objetivos principales: discutir la palabra "representación" en algunas de sus diversas acepciones, sobre todo en los estudios de las ciencias humanas, y presentar algunas imágenes o representaciones de profesor que habitan el profesional, resultantes del análisis de un texto tomado de la internet; mismo si, al término, el autor del texto se revela como no siendo un profesor, las imágenes encontradas remeten à la idea que el profesor contemporáneo se encuentra entre el pasado y el presente, entre representaciones "tradicionales", idealizadas, de un profesional que intente educar y instruir el alumno y de un profesional que necesita se adaptar al momento histórico-social en el cual se encuentra, inserindose en las normas de la escuela y de la consumación, entre el sujeto del deseo y el sujeto del imaginario. La orientación teórica adoptada se constituye del discurso, incluyéndose la psicoanálisis lacaniana y la desconstrucción, que denominamos "abordaje discursivo-deconstructivista".

Palabras clave: Discurso; Desconstrucción; Representaciones; Sujeto; Enseñanza

\section{REFERÊNCIAS}

AIDÉ, Lorenzo. Profissão: professor. Educação Pública- biblioteca, sem data. Disponível em: http://www.educacaopublica.rj.gov.br/biblioteca/educacao/0033.html. Acesso em: 23 Jun. 2015. 
CORACINI,Maria José.

AUTHIER-REVUZ, Jacqueline. Palavras incertas: as não coincidências do dizer. Campinas: Editora da UNICAMP, 1998.

BERRY, Nicole. O Sentimento de Identidade. Trad.: Maria José Coracini. São Paulo: Escuta, 1991.

CORACINI, Maria José.Discurso, Entre a Memória e o Esquecimento: fragmentos de uma história de vida. In CORACINI, M.J. \& GHIRALDELLO, C. M. (eds). Nas Malhas do Discurso: Memória, Imaginário e Subjetividade. Campinas (SP): Pontes Editores, 2011, 23-74.

CORACINI, Maria José. Um Fazer Persuasivo: o discurso subjetivo da ciência. Campinas (SP): Pontes, 2007, $2^{\mathrm{a}}$ edição.

CORACINI, Maria José. Entre adquirir e aprender uma língua. Bakhtiniana: Revista de Estudos do Discurso. v. 9, n. 2, 2014a, p. 4-24.

CORACINI, Maria José. Entre a modernidade e a pós-modernidade: discurso e ensino. Dossiê Educação, pesquisa e linguagem: encontros e atravessamentos Revista Educação da PUCRS, vol.37, n. 3, 2014b. Disponível em: revistaseletronicas.pucrs.br/ojs/index.php/faced/article/view/181482014 Acesso em: 23 Jun.

DERRIDA, Jacques. Le Monolinguisme de l'autre. Paris: Gallimard, 1996.

DERRIDA, Jacques. De lagrammatologie. Paris: LesÉditions de Minuit, 1967.

DERRIDA, Jacques. Mal d'Archive: une impression freudienne. Paris: Galilée, 1995.

DIAS, Maria das Graças Villela. O Sintoma: de Freud a Lacan. Psicologia em estudo, vol.11, $\mathrm{n}$. 2 Maringá Maio/Ag. 2006, s/página.

ECKERT-HOFF, Beatriz Maria.O falar de si como (des)construção de identidades $e$ subjetividades no processo de formação do sujeito-professor. Orientadora: Maria José Rodrigues Faria Coracini. Tese de doutorado: Departamento de Linguística Aplicada, 2004.

FIORIN, José Luiz. Linguagem e ideologia. São Paulo: Ática, 2002.

FOUCAULT, Michel. "Les Mots et les Choses", 1966. In: DitsetEcrits I. Paris: Gallimard, 2001a. 1966.

Les mots et les choses:Unearchéologie des sciences humaines. Paris: ÉditionsGallimard, Nietzsche, Freud, Marx, 1967. In: DitsetEcrits I. Paris: Gallimard, 2001b. 
REPRESENTAÇÕES DE PROFESSOR: ENTRE O PASSADO E O PRESENTE

. L'ordredudiscours:LeçoninauguraleauCollège de France prononcéele 2 de décembre 1970.Paris: Gallimard, 1971.

A Vida dos Homens Infames. In:

Estratégia, Poder-Saber. 2ed. Rio de Janeiro:

Forense Universitária, 2006.

FREUD, Sigmund. (1895) Projeto para uma psicologia científica. Edição StandartBrasileira das Obras Psicológicas Completas. Rio de Janeiro: Imago, 1996a.

. (1911) "Formulações sobre os dois princípios de funcionamento mental". In: Edição Standard Brasileira das Obras Psicológicas Completas, Vol. XII, p. 419-440. Rio de Janeiro: Imago, 1985.

(1917). Os caminhos da formação dos sintomas. Trad.: J. Salomão. Edição Standard Brasileira das Obras Psicológicas Completas, Vol. XVI, p. 419-440. Rio de Janeiro: Imago, 1980.

. (1938). O mal-estar na civilização. In: Obras psicológicas completas de Sigmund Freud: edição standard brasileira. Rio de Janeiro: Imago, $1996 \mathrm{~b}$.

HYRIGOYEN, Marie-France. Le Harcèlement moral au travail. Paris: PUF, 2014.

HOUAISS, Antonio. Grande Dicionário Houaiss da Língua Portuguesa. Rio de Janeiro: Instituto Houaiss, 2001.

LACAN, Jacques. (1949). O estádio do espelho como formador da função do eu. In Escritos. Rio de Janeiro: Jorge Zahar,1998; p. 96-103.

\section{Zahar, 1998.}

(1957-1958). O seminário livro 5: as formações do inconsciente. Rio de Janeiro: Jorge

. Seminário - Livro XVIII - "De um Discurso que não fosse semblante", Rio de Janeiro:

Jorge Zahar, 2009.

. (1966-67) O Seminário, Livro XIV - “A lógica do Fantasma”. Publicação não comercial exclusiva para os membros de Centro de Estudos Freudianos do Recife, 2008.

MOSCOVICI, Serge. Representações sociais: investigações em psicologia social. Trad.: Pedrinho A. Guareschi. 5. ed. Petrópolis, RJ: Vozes, 2007.

NÖTH, Winfried. Panorama da semiótica - de Platão a Peirce. São Paulo: Annablume, 1995. 
CORACINI,Maria José.

PALMER, S.E. Fundamental Aspects of Cognitive Representation. In E. ROSCH e B.B. LLOYD (eds) Cognition and Caracterization. Hillsdale, NJ: Lawrence Erlbaum Associates, 1978, p. 259303.

SANTAELLA, L.; NÖTH, W..Imagem - cognição, semiótica, mídia. São Paulo: Iluminuras, 1999.

SOUZA, Richer Fernando Borges de. Foucault: o mundo como linguagem e como representação. Dissertação de Mestrado, Programa de PGraduação em Filosofia da Pontifil̈cia Universidade CatoÏlica do Rio Grande do Sul (PUCRS), 2012.

ROSA, M.T. da; RUBBO, D., PEIXOTO, M.. Discurso, Desconstrução e Psicanálise no campo da Linguística Aplicada:(du)elos e (des)caminhos, Revista Delta-Documentação e Estudos em Linguística Teórica e Aplicada, vol. 31, n. Especial, 2015. Disponível em: http://revistas.pucsp.br/index.php/delta/article/view/22226/0. Acesso em: 23 Jun. 2015.

RUMELHART, David E., \& NORMAN, Donald A. (1988).Representation in memory. In R. C. Atkinson, R. J. Herrnstein, G. Lindzey, \& R. D. Luce (eds.), Stevens' Handbook of Experimental Psychology, 2nd edition. New York: Wiley.

SILVEIRA, Fernando de Almeida. Michel Foucault e construção discursiva do corpo moderno e sua relação com a psicologia. Psicologia em Estudo, vol. 13, no 4, Maringá, 2008. Disponível em: http://www.scielo.br/scielo.php?pid=S141373722008000400011\&script=sci_arttext.

STÜBE, Ângela Derlise. Tramas da subjetividade no espaço entre-línguas: narrativas de professores de língua portuguesa em contexto de imigração. Orientadora: Maria José Rodrigues Faria Coracini. Tese de doutorado: Departamento de Linguística Aplicada, 2008.

Tarauacá Notícias: Exerça-a dia a dia(1/12/2014, 15h30). Disponível em:

http://tarauacanoticias.blogspot.co.at/2011/09/sou-um-professor-que-pensa.html. Acesso em: 23 Jun. 2015.

WANNER, Maria Celeste de Almeida. Repensando a representação. Paisagens sígnicas: uma reflexão sobre as artes visuais contemporâneas [online]. Salvador: EDUFBA, 2010. http://books.scielo.org (consulta em 17/12, 12h).

Data de recebimento: 02/04/2015

Data de aceite: 04/04/2015 